\title{
Axillary Lymph Node Dissection without Prior Sentinel Lymph Node Biopsy
}

National Cancer Institute

\section{Source}

National Cancer Institute. Axillary Lymph Node Dissection without Prior Sentinel Lymph Node Biopsy. NCl Thesaurus. Code C105784.

A surgical procedure in which the axillary lymph node group is dissected and removed without prior removal and examination of the sentinel lymph node. 